\title{
Internet of Things Based Systems for Food Safety Management
}

\author{
Mihai DOINEA, Cătălin BOJA, Lorena BATAGAN, Cristian TOMA, Marius POPA \\ Bucharest University of Economic Studies, Bucharest, Romania \\ mihai.doinea@ie.ase.ro, catalin.boja@ie.ase.ro,lorena.batagan@ie.ase.ro, \\ cristian.toma@ie.ase.ro,marius.popa@ie.ase.ro
}

The paper is highlighting the advantages of integrating technologies and digital standards in public politics for protecting consumer rights. Today's globalization of food production chains, their extensive complexity and limitations arising from manual insertion and data processing of products information make it impossible for consumers the task of being informed in realtime. This obstacle can be overcome, and the current level of technology and low implementation costs allow full automation of this process. We propose a sensors network architecture based on Internet of Things (IoT) components, which is using autonomous embedded modules and radio identification tags (RFID) that will automatically collect data, covering the entire life cycle of the food product and all the factors that influence its chemical composition. This architecture offers consumers complete data about their food products and how their components were obtained.

Keywords: Consumer Rights, Open Data, Digital Society, Food Safety, Internet of Things

\section{Introduction}

For the moment it is evident that the new trend is to use to the right value the openness of data. The big volumes, complexity, openness of data determine a new mode of management and new technological safeguards for privacy.

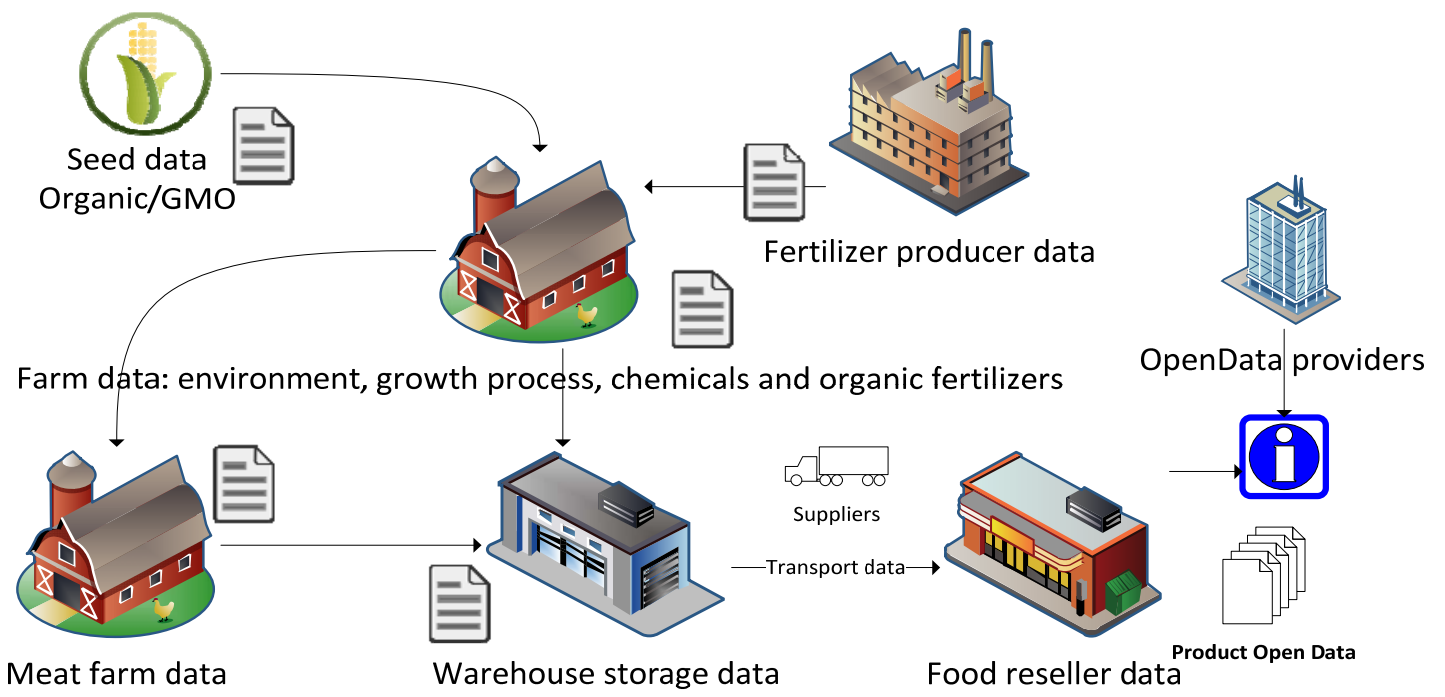

Fig. 1. Open data sources for food safety

Related to food safety, an open data environment is a complex architecture as it includes multiple data sources specific to various economic fields (figure no. 1). Each layer of information is added by a direct or indirect participant in the food production ecosystem:

- Seeds and genetic material providers are the starting point for the entire food production chain. Using electronic labels the farms can record if the seeds or the genetic material is or not genetically modified.

- Fertilizers providers will provide information about the chemical composition of these products or the

- The agricultural farm and its surrounding 
environment. The quality of fresh fruits and vegetables are influenced by the treatments made by the farmer but also by the surrounded environment. The proximity of a large industrial complex may contaminate the products.

- The animal growing farms must provide information in how the animals are reproduced and also information on the food supply chain used to deliver nutrients used to grow the livestock.

- The food additives producers must provide the scientific and chemical name of the additive. These can be correlated with Open Data libraries that provide further information on long term effect on human health if they are consumed;

- The food processing industry

- The goods transporter must provide required light and temperature conditions all the time and through the entire journey.

- The local food warehouses must provide proper storage facilities and must deliver food products before they reach their validity term;
- The local markets, supermarkets and other food resellers

- Public or governmental organizations that provide access to knowledge (A2K) and Open Data repositories

Once all this data for all these sources is recorded and publicly available in Open Data repositories there is a matter of seconds and customer culture and responsibility to access it and query it in the store. Then the consumer will have all the data needed to take a fully aware decision on buying or not that product. This is also in concordance with Europa 2020 strategy [19].

\section{IoT based food management system}

Food management systems are useful tools that helps analyze food related activities in order to optimize costs. A quickly search on Google Trends of the term food management reveals an almost constant trend from 2005 (figure no. 2) till now with regards to management procedures in food related activities.
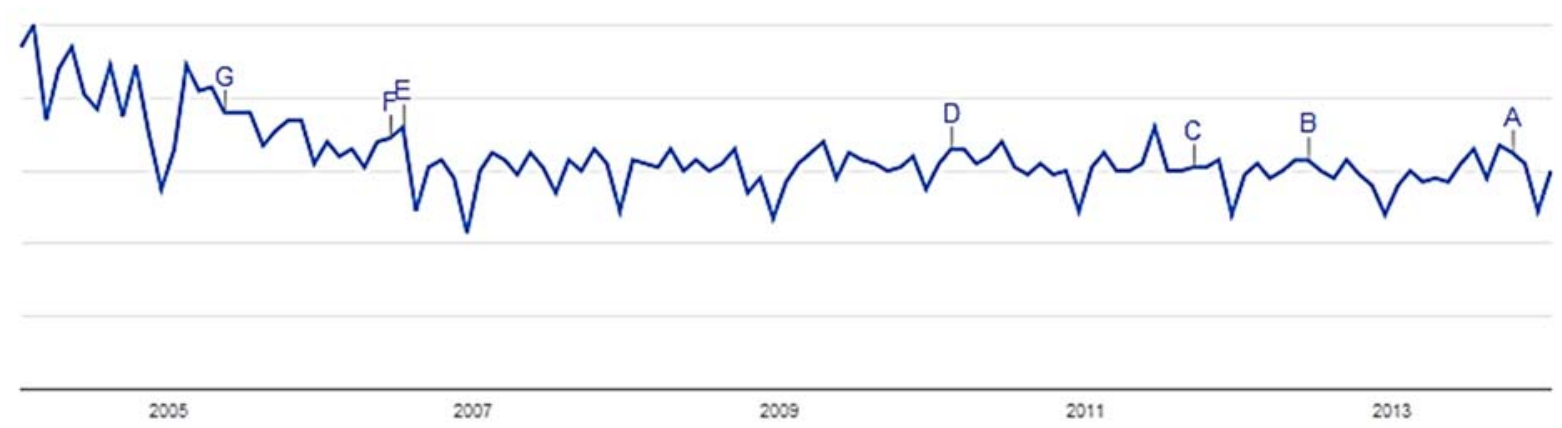

Fig. 2. Food management search trend Source: Google trends

Most of those searches show interest in undeveloped countries such as Kenya, Nigeria and India (figure no. 3), whereas the most correlated words with the food management syntagma are safety and services. The regional interest shows represent the search volume relative to the highest value of search results which is always $100 \%$. From this we can deduce that food management systems are playing a vital role in food safety and food services, helping those two areas to bring forth and improve the quality for consumers. 


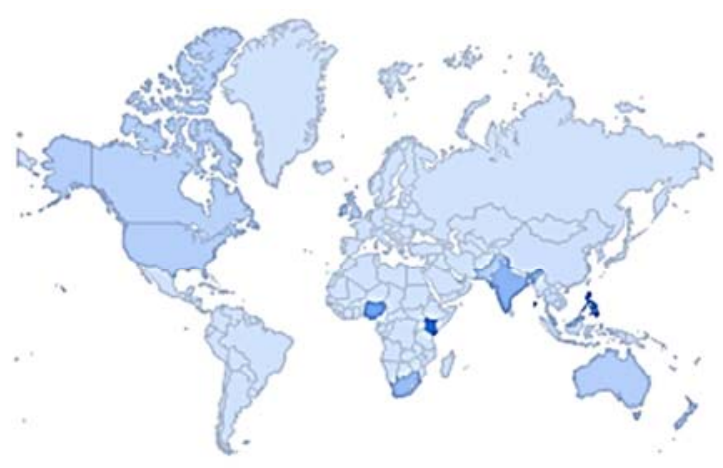

\begin{tabular}{ll} 
Kenya & 100 \\
\hline Philippines & 83 \\
\hline Nigeria & 65 \\
\hline India & $48 \square$ \\
\hline Singapore & $41 \square$ \\
\hline South Africa & $39 \square$ \\
\hline Malaysia & $32 \square$ \\
\hline
\end{tabular}

Fig. 3. Food management regional interest Source: Google trends

In the open data context, food management systems have greatly improved because of the easiness in which data is gathered by means of Internet of Things [1], [5] infrastructures. Big data is a concept now with great potential in providing trustful and reliable results for the entire community.

\section{Results and Discussions}

By using a deployed Internet of Things infrastructure with two main types of sensors RFID/NFC tags [9] and smart-objects embedded in the transportation vehicles and on the containers, data can be obtained from gateways within food production companies, supermarkets, smart refrigerators and other food processors parties, in order to dynamically track food ingredients, optimize the route from production till final consumer or stop the delivery of the goods if the transportation conditions, like temperature, are not provided all the time. The main data-flows of a food management system consist from:

- Collecting necessary info from the sensors, such as: cans and containers emptiness percentage (IoT Sensor) and identity (RFID tags); information from public smart recycling bins; retailers/markets dynamic requests regarding new deliveries or available stocks; info about the garbage/waste selection pre-processing (glass, plastic, paper, etc.); weather conditions (humidity, pollution, etc.) needed for environmental monitoring; proteins, calories and other food levels ingredients; data is collected from the IoT sensors and WSNs (Wireless Sensors Networks) using IoT gateways deployed in food processing and temporary warehouses areas;

- Dynamically re-routing the provisioning vehicles in real time traffic to reach the closest client based on the IoT collected data regarding the freshness of delivered goods. The re-routing is based on optimized critical paths obtained according with mathematical models, which will take as input data collected from IoT sensors and it will integrate a telematics fleet-vehicles management system;

- An instant payment service can be implemented, taking into account secure payment solutions (mobile, Internet, micro-payments, bank credit/debit cards via payment gateways) available in the market, in order to dismiss cashiers and track faster the levels of goods that are being bought faster than others; an analyze can be made on not so much sold products to benefit of special offers that will increase selling levels;

- All the data collected from the sensors, it will ensure the pre-requisites for an enhanced and optimized food labeling process and management, for providing environmental protection mechanisms, as well as obtaining an environmental monitoring system (CO2 emissions, pollution indicators, etc.), to reduce the production, distribution and wasting costs.

The overview of the Eco-SMART project is 
depicted in figure 4.

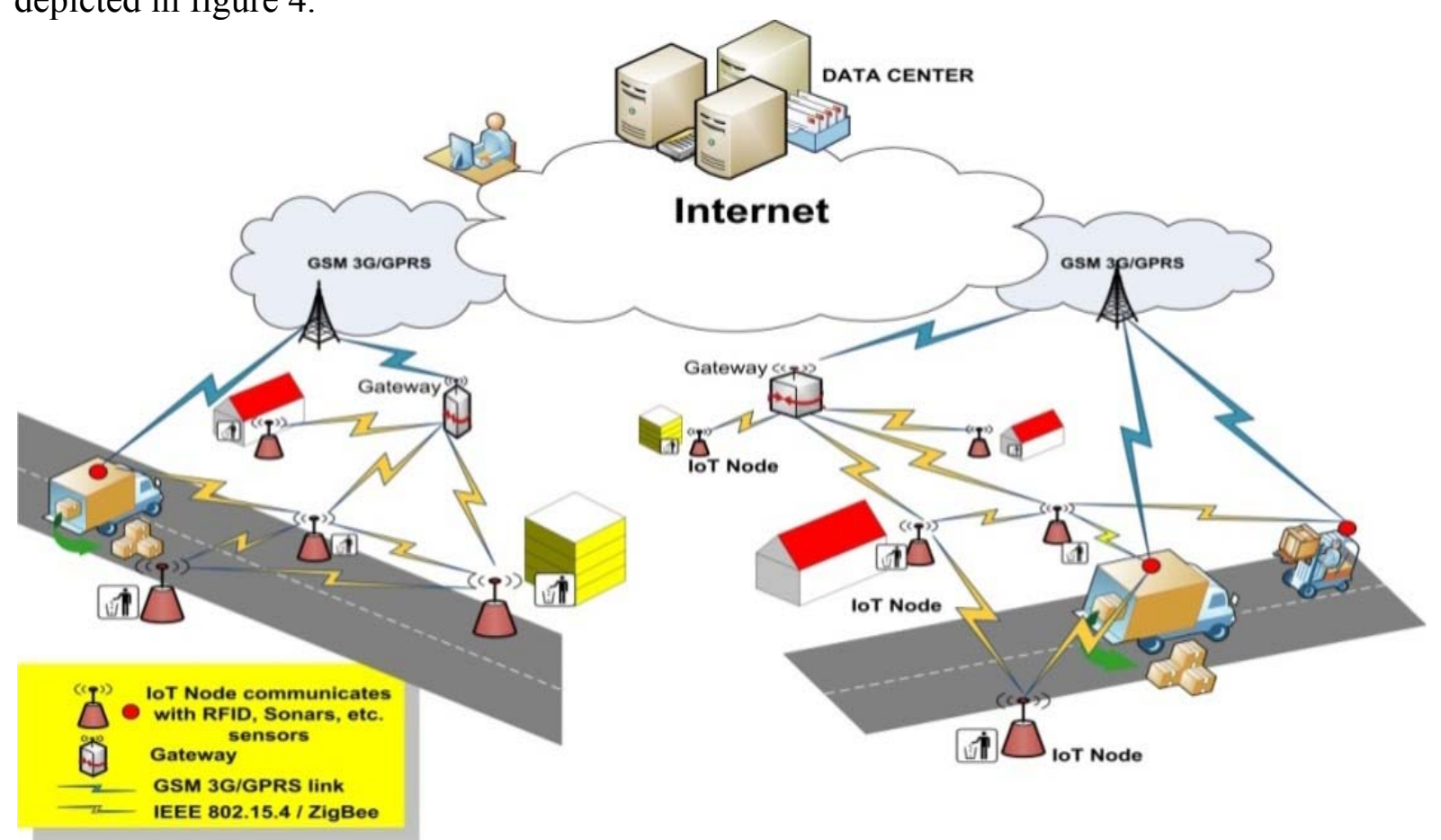

Fig. 4. Eco-SMART Project Overview Architecture

The proposed system architecture is based on the Internet of Things (IoT) infrastructure with cybernetic feed-back loop approach in design, that gets sensor-data processed it in real time and generates system behavior changes. Of course, the system architecture may be modified after the research, analysis and design task and activities from workpackages according with best-practice in the field, state of the art and the focus groups necessities. Also, as stated in [12], the software embedded in such systems has to be tested thoroughly before going in production.

The applied research results are packaged into an integrated solution, which contains: FrontEnd, Secure Middleware, Back-End sub-systems. All of these components interact with each other providing IoT Smart System architecture based on the following n-tier design pattern:

- S1: Sensors and IoT Gateways / Smart Objects Sub-system (Front-End Context Aware Tier)

- S2: Mobile and Vehicle Embedded Devices Sub-system (Front-end)

- S3: IoT Silos/Micro-cloud Infrastructure Sub-system - containing modules for (Back-end):
- Heterogeneous Sensors Data Acquisition Collection + M2M Proxy and Gateway + Micro-cloud IoT instances for HPC (High Performance Computer) and HTC (High Throughput Computing) green computing;

- S4: IT Cloud, Data and Processing Center Sub-system - containing modules for (Back-end)

- GIS (Geographical Information Systems), POI (Point of Interests) Maps and Graph Routing + IT Cloud/P2P (Peer2Peer) for implementing the mathematical models in order to obtain dynamic minimal paths/routes calculation in HTC (High Throughput Computing) and HPC (High Performance Computing) approach, according with the received data from the sensors, vehicles and citizens;

- Traffic and Fleet Management;

- BI - Business Intelligence for automated decisions plus ERP Enterprise Resource Planning for resources management plus ESB Enterprise Service Bus and SOA - 
Service Oriented Architecture Modules for data flow orchestration and Payment and Billing for citizens and companies;

- Mobile (SMS/Smart-Mobile-App) and Web for the project web-services, web-portal and mobile convergence access (from the end-users access);

- S5: Secure Middleware Sub-system contains modules in Front-End and BackEnd, which are responsible with data communications implementation (REST, WS, etc.), M2M (Machine to Machine) data structures exchange, and secure messages routing. The solution integrates several key actors in the food chain management, starting from suppliers of basic ingredients to products manufacturers which are delivering goods to retailers and ending on shopper's shelves. In all of these stages RFID tags and other IoT devices can be used to read food description data, comparing food ingredients with healthy classification tables and creating strategies for optimization purposes (figure no. 5).

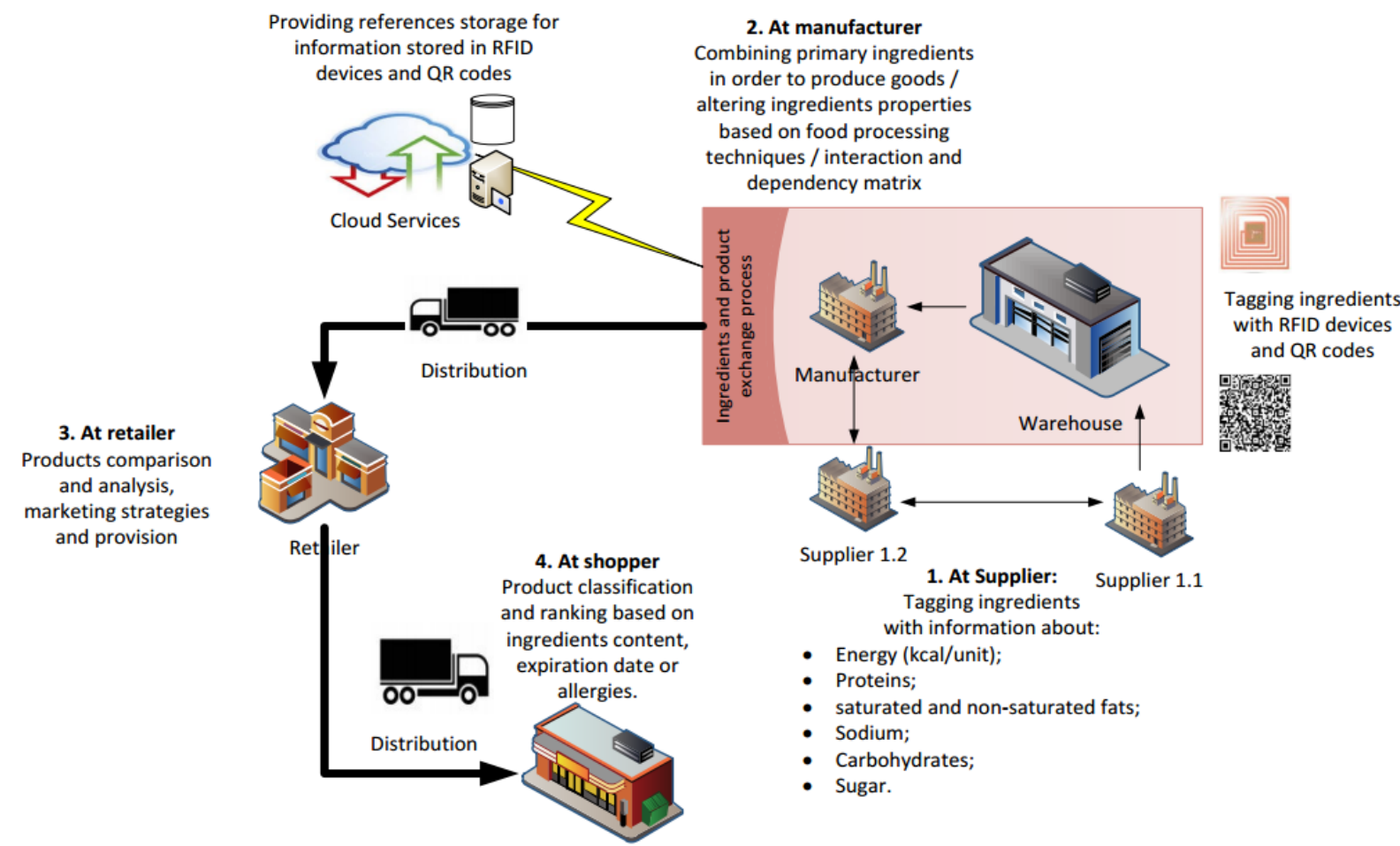

Fig. 5. Food management system implementing food labeling

The state of art is divided in two levels: solution level and technical level. At solution level, there are partial solutions delivered in EU or US, but without full achievements of the objectives from Eco-SMART project. There are solutions for parts from the "Smart Cities" applications in E.U. in Santander, without waste management [7], Helsinki, only City sensors data map, and different partial solutions implemented in U.S., like Boston, [10] and Cleveland, [6]. For the moment the solution from U.S. are not presenting possible integration with Smart Cities IoT infrastructures. The Boston solution uses BigBellySolar smart trash bin [2] in order to collect the public waste from the streets, but they are not having a smart IoT infrastructure deployed for route collection optimization. In terms of technologies as state of the art Internet of Things (IoT) [1] is at confluence of: RFID, WSN, M2M and SCADA topics [3], [4] and [18]. There are a lot of standards for IoT middleware, sensors and components/gateways. An overview for IoT boards useful as nodes or gateways is depicted Pulido [13] (2013). Typically Arduino and Intel Galileo board might be IoT nodes for sensors data collection and Raspberry Pi might be the hardware support 
for IoT gateways. For micro-cloud instances in back-end a state of art approach is to use Ninja Blocks, modified BeagleBone boards. An overview of technologies from IoT is described by Toma, Ciurea and Ivan [15] and is the support base for all solutions from "Smart Cities" including "Smart Waste Management".

\section{IoT - Internet of Things}
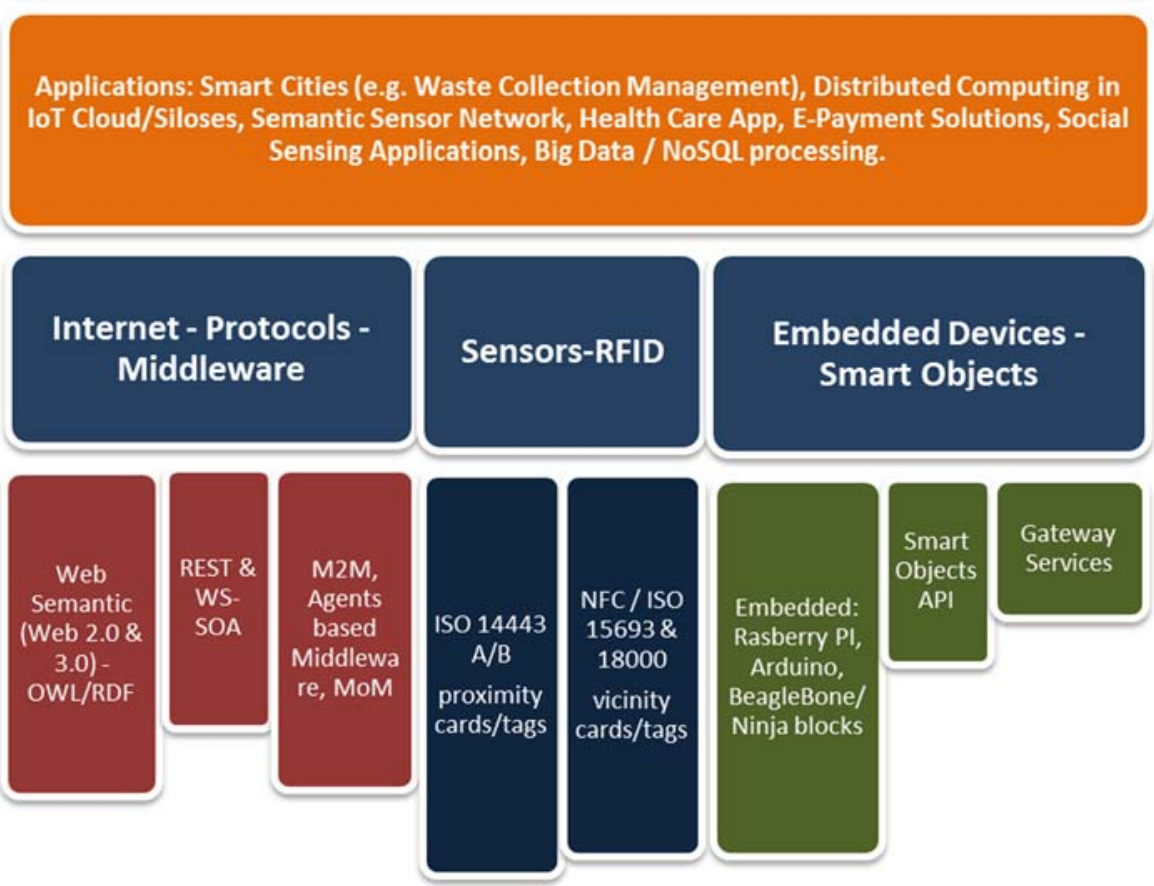

Fig. 6. IoT - Internet of Things technologies (not-complete overview) Source: Toma, Ciurea and Ivan, 2013, p. 126

For the state of the art of the middleware in Wireless sensor Network (WSN) and communications protocols, it is taken into account as radio transport standards the ZigBee, WiMax, WiFi, Bluetooth but not limited to them. Another important issue regarding technological approaches is security and quality of the solution. For QoS, besides the bandwidth, distances and reliability of the subsystems, there are sensitive issues regarding the security such as: tag cloning and identity theft, access rights to data, authenticity-integrity plus non-repudiation, capture of personal data, retention of personal data, IoT nodes/sensors destruction, transmission destruction using interfering signals, flooding a network with wrong alerts denial of service attacks, etc. Based on these elements we performed a SWOT analysis (Table 1). 
Table 1. SWOT Analysis of IoT

\begin{tabular}{|c|c|c|c|}
\hline Strengths & Weaknesses & Opportunities & Threats \\
\hline $\begin{array}{l}\text { - Saving time and } \\
\text { quickly resolving } \\
\text { issues; } \\
\text { - Saving money; } \\
\text { - Increase collabo- } \\
\text { ration. }\end{array}$ & $\begin{array}{l}\text { - The need for a } \\
\text { standardization pro- } \\
\text { cess; } \\
\text { - Devices from differ- } \\
\text { ent companies will } \\
\text { not be able to talk to } \\
\text { one another; } \\
\text { - High costs of imple- } \\
\text { mentation; } \\
\text { - The need for good } \\
\text { employers how con- } \\
\text { tinuously update } \\
\text { their knowledge; } \\
\text { - A uniform approach } \\
\text { to implement IoT in } \\
\text { the various business. }\end{array}$ & $\begin{array}{l}\text { - Excellent oppor- } \\
\text { tunities for effi- } \\
\text { ciency. } \\
\text { - Increase interop- } \\
\text { erability; } \\
\text { - Saving the envi- } \\
\text { ronment and re- } \\
\text { ducing climate } \\
\text { change. }\end{array}$ & $\begin{array}{l}\text { - People's fear of } \\
\text { what technology } \\
\text { can do. } \\
\text { People worry } \\
\text { about how much } \\
\text { information de- } \\
\text { vices may be } \\
\text { able to collect } \\
\text { about them and } \\
\text { with whom and } \\
\text { how that infor- } \\
\text { mation might be } \\
\text { shared. } \\
\text { - Manipulation of } \\
\text { people. }\end{array}$ \\
\hline
\end{tabular}

The food management system main advantages are given by all these solutions from interdisciplinary fields that maximize the way in which food products are produced, delivered and recycled:

- enhancing the people awareness regarding food management topics and issues within media events;

- food provisioning track optimization with respect to food validity and conservation methods; this lowers the risks for spoilage and possible contaminations and foodborne illnesses;

- increase productivity, as human workers no longer need to manually insert information in the system;

- fast access to information as consumers can use in store information portals or their own smartphones to scan and read electronic labels and get the detailed information on production chain and product composition;

- optimizing the food waste processes by easily classifying food ingredients and products validity.

\section{Big data analysis}

Big data instruments provides the easy way to create knowledge from the immense volume of data stored in cloud. In the context of food safety management, the entire track of each ingredient which is part of a product and even the processes that might affect its qualities like storage, transportation and manipulation can be easily accessed and used for various computation in order to give a reliable status of the final product.

Scientist have tackled this field for quite a lot and now existing instruments are offering valuable insights into what big data is and how it can help to:

- process optimization - optimization is vital for evolution, so in order to make better optimization one needs to have reliable information about the process subject of optimization; all these knowledge can come from big data analysis which might provide reliable data in order to approach the optimization;

- take informed decisions - the concept of data-driven decision is based on an automatically process driven by data; if input data is provided from a big data analysis operation, than decisions can rely on correct and real-time variable that can positively influence the decision processes;

- understand behavior - behavior always was and will be the main variable in the 
equation of an economic process; is not sufficient to know which is the input of a system in order to determine its output; one may need also to understand the behavior, the black box, in order to compute, as good as possible, the outcome, the results; for this reason big data analysis can cast significant information on how a process behaves and improve the outcome;

- engaging resources more efficiently - in order to engage resources into an economic process it is absolutely necessary to have as many data as possible with regards on how those resources will impact the entire process; predictive analytics can compute alternative solutions based on different configurations of input factors.

Large volume of information come now from a various network of sensors that are all connected and interconnected in real time, pumping huge amounts of data that can't be exploited without the existence of this area of science which is, with no doubt, big data analysis.

As mentioned also in [20] the economy will gain 5-6 percent due to decisions taken based on data-driven analysis. Overall, big data analysis means that nothing can be lost if it's properly managed. In food industry everything must be recorded and tagged in order to be able to give reliable information to consumers about the quality of the product they are interested.

To benefit from this huge amounts of data, system must face another issue concerning the hardware capabilities. For responding to the question related with how much processing power is needed for big data analysis first another answer should be given to the following aspects:

- how fast the results should be provided in order to have fast results a system must have huge amounts of processing resources;

- how thorough the analysis should go - as the analysis advances, and more and more data is ingested for processing, the result should be more reliable.
In order to adapt the system to the growing need of processing power demanded by the large volume of data stored, hardware must be scaled, as presented in [21]. In big data there are two ways to cope with the large volume of data that needs to be processed:

- horizontal scaling - this means distributing the need of processing resources on horizontal, distributing the workload across other machines; examples of horizontal scaling: peer-to-peer networks; Apache Hadoop or Spark paradigm;

- vertical scaling - for this type of scaling the hardware must be reconfigured by adding new units of processors and memory; examples of vertical scaling: HPC clusters, multicore CPU or GPU.

Big data analysis rises a couple of problems as presented above:

- redundancy is a big issue in big data analysis because if redundant data isn't eliminated through data reducing algorithms those irrelevant aspects will influence the final result in a negative way;

- irrelevant directions due to lack of data is also a major issue because in order to obtain a reliable result a big data analysis must have relevant data for the examined area.

In food safety management the results can influence the consumer so the final product will or will not be taken out of the market. So, to give good results, a big data analysis must advance as deep as possible, and be as quickly as it can.

\section{Conclusions}

From a producer involved in a stage of the food production and delivery chain, the IoT food management system is providing a solution of a logistics problem because it generates an environment in which there are few or none unknowns about the right product in the right quantity at the right time at the right place in the right condition and at the right price [16], [17]. For the consumer, the right to be informed will be backed up by the right information.

There are three milestones that once achieved 
will open up new horizons in our society concerning consumer protection and rights. One is the technology milestone that requires the development of an autonomous sensor infrastructure that will acquire data. The second milestone is the implementation of an access to knowledge infrastructure based on public policies and Open Data repositories [7]. The last milestone is building or imposing a consumer oriented culture at food producer's level that will enhance the benefits for providing public data about the entire process.

\section{Acknowledgment}

This paper is supported by the Sectorial Operational Programme Human Resources Development (SOP HRD), financed from the European Social Fund and by the Romanian Government under the contract number SOP HRD/159/1.5/S/136077.

\section{References}

[1] Ashton, K., 2009. That 'Internet of Things' Thing, in the real world things matter more than ideas. [online] RFID Journal. Available at: < http://www.rfidjournal.com > [Accessed 28 March 2015]

[2] BigBelly Solar, 2013. A Smart Trash Can? [online] Available at: <http://bigbellysolar.com/solutions/stations/smartbelly/> [Accessed 28 March 2015]

[3] Boswarthick, D., Elloumi, O. and Hersent, O. eds. 2012. M2M Communications: A Systems Approach. 1st ed. New York: Wiley.

[4] Chaouchi, H. ed., 2010. The Internet of Things: Connecting Objects (ISTE). 1st ed. New York: Wiley.

[5] Commission of the European Communities COM(2009) 278 final of 18 June 2009 on Internet of Things - An action plan for Europe. [online] Available at: $<$ http://eur-lex.europa.eu/LexUriServ/LexUriServ.do?uri=COM:2009:0278:FIN:EN:P DF $>$, [Accessed 10 September 2013]

[6] Fickes, M., 2010. The Spirit of Radio. [online] Waste 360. Available at: http://waste360.com/Collec-
tions_And_Transfer/rfid-waste-collection-201010 [Accessed 15 January 2014]

[7] Iglesias C., 2013. A year of Open Data in the EMEA region - European Public Sector Information Platform, [pdf] Topic Report No. 2013/12, Available at: $<$ http://www.epsiplatform.eu/sites/default/files/A\%20year $\% 20$ of $\% 200 p e n \%$ 20Data $\% 20$ in $\% 20$ the $\% 20$ EMEA $\% 20$ region_0.pdf $>$ [Accessed 18 November 2013]

[8] Libelium, 2013. 50 Sensor Applications for a Smarter World. [online] Available at:

$<$ http://www.li-

belium.com/top_50_iot_sensor_applications_ranking/> [Accessed 5 December 2013]

[9] Lixandroiu, R. 2006. A Model of Traceability for Equipments using RFID Tehnologies within an Integrated System, Informatica Economica, 10(2), pp. 124128

[10] Morris, C., 2011. US Boston implementation of solar powered waste compacting and recycling bins. [online] BostInno. Available at:

$<$ http://bostinno.streetwise.co/2011/02/02/bigbelly-doublesrevenues-in-2010-boston-due-for-acitywide-trash-makeover/> [Accessed 15 January 2014]

[11] Organization for Economic Co-operation and Development, 2007. OECD Principles and Guidelines for Access to Research Data from Public Funding, Retrieved January 25, 2014, Available online at http://www.oecd.org/sti/scitech/38500813.pdf

[12] Pocatilu, P., Ivan, I., 2012. A Genetic Algorithm-based System for Automatic Control of Test Data Generation, Studies in Informatics and Control, 22(2)/2013, pp. 219-226

[13] Pulido, A., 2013. Open Smart Cities I: Open Source Internet of Things. [online] Observatorio Nacional del Software de Fuentes Abiertas. Available at: $<\mathrm{http}$ ://observatorio.cenatic.es/in- 
dex.php?option $=$ com_content\&view $=$ article\&id=807:open-smart-cities-i-openinternet-of-things\&catid=94:tecnologia\&Itemid $=137>$ [Accessed 5 December 2013]

[14] Schwab K., 2013. The Global Competitiveness Report 2013-2014, World Economic Forum, [online] Available at: $<$ http://www3.weforum.org/docs/WEF_GlobalCompetitivenessReport 2013-14 .pdf>, [Accessed 3 September 2013]

[15] Toma, C., Ciurea, C., Ivan, I, 2013. Approaches on Internet of Things Solutions, Journal of Mobile, Embedded and Distributed Systems, 5(3), pp.124-129.

[16] Uckelmann, D., Harrisson, M., and Michahelles, F., 2011. An Architectural Approach Towards the Future Internet of Things. In Uckelmann, D., Harrisson, M., and Michahelles, F., eds. 2011. Architecting the Internet of Things. Berlin: Springer. pp. 1-24.

[17] U.S. Food and Drug Administration,
2007. Food Protection Plan: An integrated strategy for protecting the nation's food supply; [pdf] Washington: Department of Health and Human Services. Available at: < http://www.ntis.gov>. [Accessed 17 November 2013]

[18] Zhou, H., 2012. The Internet of Things in the Cloud: A Middleware Perspective, New York: CRC Press.

[19] Ion, A.M., Vespan D., "Human sustainable development in the context of Europa 2020 strategy," Proc. of the 15th EBES Conference - Lisbon, January 8-10, 2015, Lisbon, Portugal", pp.98, EBES Publications, Istanbul, Turkey

[20] Tene, O. and Polonetsky, J. 2012. Big data for all: Privacy and user control in the age of analytics, Northwestern Journal of Intellectual Property 11(5):239273.

[21] Dilpreet, S. and Chandan R.. 2014, A survey on platforms for big data analytics, Journal of Big Data, vol. 2, 20 pg.

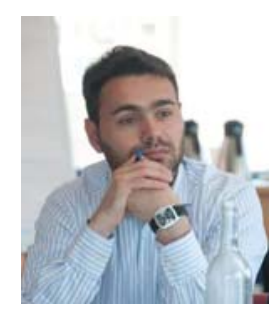

Mihai DOINEA has a $\mathrm{PhD}$ in the field of Economic Informatics, within Academy of Economic Studies, Bucharest, Romania. His PhD thesis tackles the field of Informatics Security, with clear objectives about finding security optimization methods in distributed applications. His research is also backed up by a master diploma in Informatics Security (2008). He is an assistant professor, teaching Data Structures and Advanced Programming Languages at the Bucharest University of Economic Studies. He published more than 30 articles in collaboration or as single author and his research interests are directed to areas such as security, distributed applications, artificial intelligence and optimization algorithms.

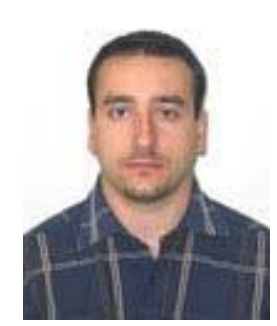

Cătălin BOJA is associate professor at the Economic Informatics and Cybernetics Department at the Academy of Economic Studies in Bucharest, Romania. In June 2004 he has graduated the Faculty of Cybernetics, Statistics and Economic Informatics at the Bucharest University of Economic Studies. He is a team member in various undergoing university research projects where he applied most of his project management knowledge. His work currently focuses on the analysis of mobile computing, information security and cryptography. He is currently holding a $\mathrm{PhD}$ degree on software optimization and on improvement of software applications performance 


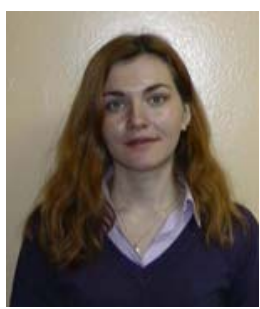

Lorena BĂTĂGAN has graduated the Faculty of Cybernetics, Statistics and Economic Informatics in 2002. She has become teaching assistant in 2002. She has been university lecturer since 2009. She is associate professor at the Faculty of Economic Cybernetics, Statistics and Informatics from Bucharest University of Economic Studies. She holds a PhD degree in Economic Cybernetics and Statistics in 2007. She is the author and co-author of 4 books and ferences, symposiums. over 50 articles in journals and proceedings of national and international con-

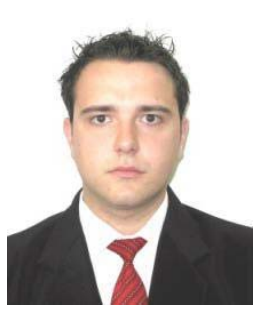

Cristian TOMA has graduated from the Faculty of Cybernetics, Statistics and Economic Informatics, Economic Informatics specialization, within Academy of Economic Studies Bucharest in 2003. He has graduated from the BRIE master program in 2005 and $\mathrm{PhD}$ stage in 2008. In present, he is associate professor at Economic Informatics and Cybernetics Department and he is member in research structures such as ECO-INFOSOC. Since the beginning - 2005 - he is scientific secretary of IT\&C Security Master Program from Bucharest University of Economic Studies and since 2006, he is in the editorial board of the SECITC - The International Conference on Security for Information Technology and Communications and JMEDS - Journal of Mobile, Embedded and Distributed Systems. His research areas are in: distributed and parallel computing, mobile applications, smart card programming, e-business and e-payment systems, network security, computer anti-viruses and viruses, secure web technologies and computational cryptography. He is teaching in Department of Economic Informatics and Cybernetics, and IT\&C Security Master program. He has published 3 books and over 50 papers in indexed reviews and conferences proceedings.

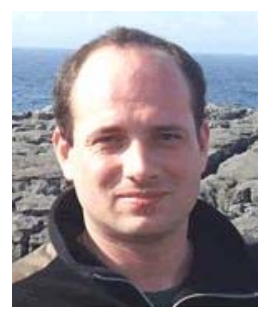

Marius POPA has graduated the Faculty of Cybernetics, Statistics and Economic Informatics in 2002. He holds a PhD diploma in Economic Cybernetics and Statistics. He joined the staff of Bucharest University of Economic Studies, teaching assistant in 2002. Currently, he is Associate Professor in Economic Informatics field and branches within Department of Economic Informatics and Cybernetics at Faculty of Economic Cybernetics, Statistics and Informatics from Bucharest University of Economic Studies. He is the author and co-author of 9 books and over 140 articles in journals and proceedings of national and international conferences, symposiums, workshops in the fields of data quality, software quality, informatics security, collaborative information systems, IT project management, software engineering. 